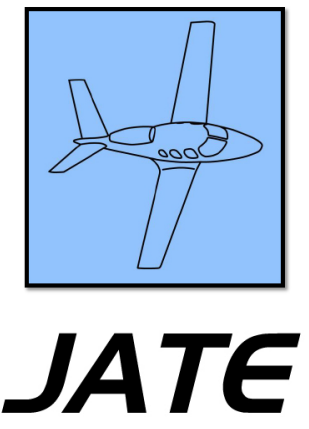

Journal of Aviation Technology and Engineering 5:1 (2015) 25-32

\title{
The Impact of the First Officer Qualification Ruling: Pilot Performance in Initial Training
}

\author{
Nancy R. Shane \\ (University of North Dakota)
}

\begin{abstract}
The intent of the First Officer Qualification (FOQ) ruling was to improve the quality of first officers flying for Part 121 carriers. In order to test this, a study was completed at a regional carrier to compare pilots hired prior to the FOQ ruling with those hired after the FOQ ruling. The study compared 232 pilots hired from 2005-2008 with 184 pilots hired from August 2013-November 2014. The pilots' date of hire as compared to the date the FOQ ruling went into effect defined the input (Source) variable. Initial training defined the output (Success) variables. The airline name and all identifying information were removed from the data set. The pilots were compared in three areas: total flight hours, training completion and extra training events. The results of the study show that, while pilots hired after the FOQ ruling had a significantly higher number of total flight hours, that group was more likely to need additional training and less likely to successfully complete training than those who were hired prior to FOQ. The study shows that there may have been some unintended consequences of the FOQ ruling and that more extensive research is needed to confirm that these results are representative of regional carriers across the industry.
\end{abstract}

Keywords: air carrier, aviation degree, first officer, first officer qualification, flight hours, flight instructor, Part 61, Part 121, pilot certification, pilot source study, pilot training, regional airline

On February 12, 2009, a Colgan Airways Q400 crashed in bad weather on approach to Buffalo Niagara International Airport (National Transportation Safety Board, 2010). In the months after the accident, the victims' families brought into question the then-current requirements and qualifications for first officers at Part 121 carriers. Because of the strong lobbying effort by the victims' families and also because of the public's demand for safer skies, a new law, Public Law 111-216, was passed by Congress in 2010 (Airline Safety and Federal Aviation Administration Extension Act of 2010). The new law went into effect in August 2013 and required all pilots, including first officers, at air carriers to have an Airline Transport Pilot (ATP)

\footnotetext{
About the Author

Nancy R. Shane has a background in both education and aviation with a master's degree in education from Harvard University and a master's degree in aeronautical science from Embry-Riddle Aeronautical University. She is also a multi-engine instrument-rated pilot and holds an aircraft dispatcher certificate. With seven years of teaching experience and an additional eight years of experience working in the commercial airline industry, Shane is currently assistant professor of aviation at Farmingdale State College. She is pursuing her doctoral degree in aerospace sciences at the University of North Dakota, where her research is focusing on pilot training, qualifications, and quality. Correspondence concerning this article should be sent to nancy.shane@my.und.edu.
} 
certificate. Prior to this ruling, first officers were only required to hold a Commercial certificate (Certification, 2014). In July 2013, the Federal Aviation Administration (FAA) made a regulatory change that defined the requirements for a Restricted ATP (R-ATP), which allowed pilots to obtain a version of the ATP in order to become first officers at air carriers. This new ruling has become known as the First Officer Qualification ruling and is informally called the FOQ ruling or simply FOQ (Federal Aviation Administration, 2013a).

There has been much discussion in the aviation industry about the FOQ ruling, its intended results and the impact of its enactment. However, this is the first formal study that has been conducted to determine whether or not the new requirement has really improved the quality of first officers and the safety of air carriers. Although a good deal of indepth research will be needed to reach a final conclusion on the impact of the ruling, this study takes a first step toward analyzing its effect by comparing total flight hours, training completion, and extra training events of first officers in initial training at a single regional airline prior to and after the FOQ ruling went into effect.

\section{Literature Review}

On August 1, 2010, Congress enacted Public Law 111-216 (PL111-216), officially known as the Airline Safety and Federal Aviation Administration Extension Act of 2010 (2010). While there are many elements contained in PL 111-216, the part most significant to the airline industry was the section that changed the qualification requirements for first officers flying for Part 121 carriers. Prior to the passing of PL 111-216, first officers were only required to hold a Commercial certificate, which required 250 total hours of flight time to obtain. The passing of PL 111-216 required first officers to hold an Airline Transport Pilot certificate, which requires 1,500 hours of total time. It also stipulated that the Federal Aviation Administration (FAA) would issue a final ruling within 36 months that would outline additional information on the ATP (Airline Safety and Federal Aviation Administration Extension Act of 2010, 2010). During that 36-month timeframe, the already-created FAA First Officer Qualification Aviation Rulemaking Committee (FOQ ARC) was working to guide the input of the final ruling (Federal Aviation Administration, 2010). Just prior to the law taking effect in August 2013, the FAA did indeed issue the final ruling, which has come to be known as the First Officer Qualification ruling or just FOQ. The FOQ ruling included specific requirements for the issuance of an Airline Transport Pilot certificate with Restricted Privileges, a new type of certificate that would allow first officers with fewer than 1,500 hours the ability to become first officers at Part 121 carriers if they met certain academic coursework requirements (Federal Aviation Administration, 2013a). The FAA was able to pass this ruling because Congress, with the passing of PL 111-216, had given the FAA the authority to use academic coursework in lieu of total flight hours.

The following are the general requirements for the awarding of an R-ATP:

Pilot must:

- Be at least 21 years old

- Hold a Commercial pilot certificate with instrument rating

- Complete the new Air Transport Pilot Certification Training Program before completing the ATP written examination (this went into effect on July 31, 2014)

- Pass the ATP written examination.

- Meet at least one of the following qualifications: Have at least 750 hours of total flight time (military pilots)

Have at least 1,000 hours total flight time and a bachelor's degree with an aviation major

Have at least 1,250 hours of total flight time and an associate degree with an aviation major

Have at least 1,500 hours of total flight time (Federal Aviation Administration, 2013a).

Advisory Circular (AC) 61-139 (Federal Aviation Administration, 2013b) outlines the requirements that institutions of higher education must meet in order to have the authority to certify the graduates of their aviation majors. This certification allows successful graduates who otherwise meet the requirements of Part 61 to apply for the R-ATP. The AC itself should be consulted for details on the requirements; however, an overview of the requirements is presented here. Institutions of higher education may be granted the authority to certify their graduates if they can meet the following requirements:

- The institution must be accredited

- The course of study must include either 30 semester hours (for reduction to 1,250 hours) or 60 semester hours (for reduction to 1,000 hours) of aviation and aviation-related coursework that has been approved by the Administrator. The degrees granted may be approved at either the associate's degree or bachelor's degree level. The approved coursework includes the following topics:

Ground and Flight Training for Certificates and Ratings

Aerodynamics and Aircraft Performance

Aircraft Systems

Aviation Human Factors

Air Traffic Control (ATC) and Airspace

Aviation Law and Regulations

Aviation Weather

Aviation Safety

- The institution must hold either a Part 141 pilot school certificate with Training Course Outlines (TCOs) approved for both ground and flight training OR hold a Part 141 pilot school certificate with TCOs approved 
for ground training and have a formal agreement with a Part 141 flight school with TCOs approved for flight training.

Based upon the degree earned, graduates of schools with institutional authority may apply for the R-ATP as long as they meet all the requirements listed in the applicable sections of Part 61.160 (Federal Aviation Administration, 2013b) and also those requirements listed in AC 61-139.

The final requirement to serve as a first officer at a Part 121 carrier is that the pilot must have either an ATP certificate and a type rating for the aircraft that he/she will fly or a R-ATP certificate and type rating for the aircraft that he/she will fly (Federal Aviation Administration, 2013a).

With these new training and certificate requirements outlined, it is necessary now to turn to the research that has been completed in order to provide a framework for this particular study. In the timeframe since the Colgan Airways accident and the announcements of new regulations shortly thereafter, there have been several studies that have researched the effects of pilot backgrounds, education, training and other variables on pilot success in airline initial training. The most notable and comprehensive of such studies is known as the Pilot Source Study, which was completed by a group of researchers who were tasked by the Aviation Accreditation Board International (AABI) to complete the original project in February 2010. The first phase of the Pilot Source Study was published in 2010, with a continuation of the study published in 2012. The purpose of the original study was to determine the characteristics of pilots hired at regional airlines from 2005-2009 and to see how those characteristics related to their success in training programs. The term "success" in the study was defined as having fewer extra training events and fewer non-completions in the training program (Smith, Bjerke, NewMyer, Niemczyk, $\&$ Hamilton, 2010). The results of the study showed that the most successful pilots were flight instructors who graduated with aviation degrees from an accredited college aviation program and had between 500 and 1,000 hours of total time (Smith et al., 2010).

In 2013 a second article was published as a continuation of the original Pilot Source Study. While looking at similar factors, this iteration of the study utilized an entirely different data set. The purpose of this phase of the study was to determine what effect college and piloting backgrounds had on extra training events, training completions, number of unsatisfactory grades in first year line observations, and the number of unsatisfactory grades in first year recurrent training for pilots in Part 121 regional airlines (Smith et al., 2013. The results of this study were consistent with those of the 2010 Pilot Source Study in that pilots with advanced training (e.g., flight instructor) who graduated with aviation degrees from accredited institutions were more successful than those without any degree or with a non-aviation degree. The study also showed that pilots with only a Commercial certificate had more training completions than those with an ATP certificate (Smith et al., 2013).

The results of both the 2010 and 2012 Pilot Source Studies are very important, especially given the regulatory landscape when it comes to pilot qualifications. The result most relevant to the current study is the determination that pilots with only a Commercial certificate had more training completions than those with an ATP certificate (Smith et al., 2013). This is relevant because, due to the new FOQ ruling, pilots with Commercial certificates are no longer eligible to work as first officers at Part 121 carriers (Federal Aviation Administration, 2013a).

In the time period since the final ruling in August 2013, there has been very little formal research on the effects of the FOQ ruling on the aviation industry as a whole. One study examined the effects on the aviation industry in general and looked at the impact of the FOQ ruling on collegiate aviation flying programs (Depperschmidt, 2013). The results showed that the ruling would have a negative effect on cost, recruitment, and retention for collegiate aviation flying programs. The study also concluded that the ruling would not improve the quality or safety of pilots (Depperschmidt, 2013). While this study is useful to collegiate aviation programs and to the industry in general, it does not address the effect of the FOQ ruling on airlines, airline pilot quality, or initial training success.

Another study set out to compare the certification requirements for the highest level of licensure in the United States, Australia, and the European Union. The results of the study showed that all have similar requirements for total flight time and instrument hours. The results also showed that the requirements for the three entities differ in the areas of cross-country time, hours in aircraft type, and minimum age for certification (Sperlak, Geske, Johnson, \& Schreckengast, 2014). While useful to get a general understanding of pilot certification requirements around the world, this study does not aim to address the impact of the new United States certification requirements within the industry.

After careful review of the literature, the author was not able to find any formal research that has been conducted on the impact of the FOQ ruling on regional air carriers. Because of this, a literature review of this specific topic is limited and cannot offer much in the way of research support or basis for understanding in this area.

\section{Design and Procedures}

This study focused on a single regional airline that was a part of the original group of airlines that participated in the Pilot Source Study. The data set utilized for those pilots hired prior to the FOQ ruling was ascertained from the researchers who conducted the Pilot Source Study (Smith 
et al., 2010). The researcher who obtained this data visited the airline and personally collected data from both pilot application files and pilot training files.

The data set utilized for those pilots hired after the FOQ ruling was collected by the researcher herself. The researcher visited the airline and personally collected data from pilot application files and pilot training files. This information was supplied by the chief pilot's office and the training department.

In order to ensure that the two data sets were comparable, the researcher of this study contacted the researcher who collected the original data prior to beginning her own data collection and verified the collection techniques, methods, and content of the data collected.

\section{Population}

The target population of this study consisted of two groups of first officers who entered initial training at a single regional airline within two different time periods. The first group of pilots was hired from 2005-2008, before the FOQ ruling was in place. The second group of pilots was hired from August 2013-November 2014, just after the FOQ ruling went into effect. The data set contained a total of 416 pilots, with 232 pilots in the first group and 184 pilots in the second group. The data set for the first group was already deidentified and sorted for analysis. The data set for the second group was deidentified and sorted by the researcher of this study.

\section{Limitations}

For the data set in the "Pre FOQ" grouping, all data for total flight hours was included in the statistical analysis in that area even if a pilot did not successfully complete training. In addition, data on extra training events was also included in the analysis even if a pilot did not successfully complete training. For the data set in the "Post FOQ" grouping, information on extra training events for pilots who began ground school in November 2014 was left out of the analysis because they had not completed the training cycle. Information on training completion was also left out of the analysis for those still in the process of training. Data on total flight hours was used for all pilots unless the information was missing from the acquired data.

In addition to the limitations discussed, there are confounding variables that were not measured that could render the conclusions less meaningful. Examples of these include the pilots' training background, education, military experience, and experience as a flight instructor; however, it is important to note that, due to the scope of this particular study, these variables were consciously omitted.

Effect size was included in the reporting for all statistically significant results. As the chi-square was used for analysis, the Phi was utilized to calculate effect size. Effect sizes were small to medium, indicating that there was a small to medium relationship between the input and the outcome.

\section{Research Questions}

1. Is there a difference in extra training events for first officers in initial training at a Part 121 regional carrier since the new FOQ ruling?

2. Is there a difference in training completions for first officers in initial training at a Part 121 regional carrier since the new FOQ ruling?

\section{Results}

\section{Descriptive Statistics: FOQ Grouping}

The regional airline where the data was collected tracks its incoming pilots by date of hire. This facilitated the grouping of the data set as either "Pre FOQ" or "Post FOQ," with August 1, 2013 as the date that separated the two groups. The data set obtained from the Pilot Source Study was gathered in 2010 and contained data on pilots who were hired from 2005-2008. The Pre FOQ group was composed of these pilots. The data set obtained by the researcher was gathered in November 2014 and contained data on pilots who were hired from August 2013-November 2014. The Post FOQ group was composed of these pilots. Table 1 shows the FOQ variable.

\section{Descriptive Statistics: Total Flight Hours}

The collected data includes information on each pilot's total flight hours. The regional airline in this study tracks the total number of flights hours based upon reports of pilots upon initial hire. The data set obtained from the Pilot Source Study contained the total flight hours for the pre FOQ group of pilots. The data set obtained by the researcher also contained the total flight hours for the post FOQ group of pilots. Because several elements of the FOQ ruling were based on total number of flight hours, this variable plays a significant role in this analysis. Among the entire data set, 415 pilot records $(99.75 \%)$ reported total flight hours. The lowest reported number of flight hours was 198, and the highest number of reported flight hours was $17,079(\mathrm{M}=1,500, \mathrm{SD}=1,960.56)$.

Table 1

FOQ grouping.

\begin{tabular}{lcc}
\hline FOQ Grouping & $\mathrm{N}$ & $\%$ \\
\hline Pre FOQ & 232 & 55.8 \\
Post FOQ & 184 & 44.2 \\
\hline
\end{tabular}

Note: $N=416$ 
Descriptive statistics for each FOQ grouping were computed to determine the mean for total flight hours for each group. See Table 2 below.

Because 1,500 hours is a pivotal delineator in the new FOQ ruling, the total flight hours were grouped into four categories based upon FOQ grouping and total flight hours. See Figures 1, 2, and 3 for number of pilots and percentage of each grouping.

\section{Outcome: Extra Training Events}

Chi-squares were calculated to test whether there was a difference in extra training events based on FOQ grouping and hour group within each FOQ grouping. Results showed that pilots hired after the FOQ ruling went into effect were more likely to require extra training than those hired before the FOQ ruling went into effect. In addition, further chisquares were calculated to test where there was a difference in extra training events based on total flight hours within the FOQ groupings. Results showed that pilots who had 1,500 or more total flight hours and who were hired after the FOQ ruling were more likely to require extra training events than those pilots with 1,500 or more total flight hours who were hired prior to the FOQ ruling taking effect. There was no significant difference in extra training events between FOQ groupings for pilots with $0-1,499$ total flight hours.

For extra training events, the nonsignificant background variable was:

- 0-1500 Hours: $\chi^{2}(1, N=103)=0.336, p=.562$.

For extra training events, the significant background variable information was:

- 1,500+ Hours: See Table 3

- Total Flight Hours: See Table 4

\section{Outcome: Training Completion}

Chi-squares were calculated to test whether there was a difference in training completion based on FOQ grouping and hour group within each FOQ grouping. Results showed that pilots hired after the FOQ ruling went into effect were less likely to complete training than those hired before the FOQ ruling went into effect. In addition, further chisquares were calculated to test where there was a difference in training completion based on total flight hours within the FOQ groupings. Results showed that pilots who had 1,500 or more total flight hours and who were hired after the FOQ

Table 2

Total flight hours within FOQ grouping.

\begin{tabular}{lccc}
\hline FOQ Grouping & $\mathrm{N}$ & Mean & Std. Deviation \\
\hline Pre FOQ & 232 & 1654.43 & 1327.08 \\
Post FOQ & 183 & 3095.10 & 2311.20 \\
\hline
\end{tabular}

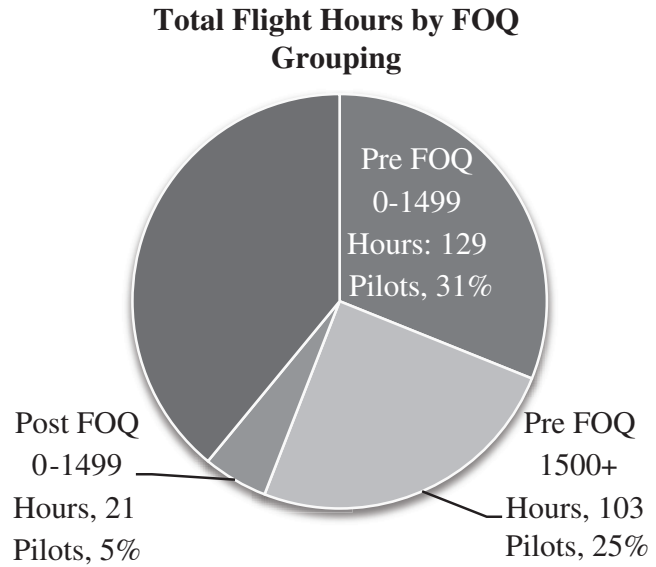

Figure 1. Description of categorical variable, total flight hours by FOQ grouping.

ruling were less likely to complete training than those pilots with 1,500 or more total flight hours who were hired prior to the FOQ ruling taking effect. There was no significant difference in training completion between FOQ groupings for pilots with $0-1,499$ total flight hours.

For training completion, the nonsignificant background variable was:

- 0-1500 Hours: $\chi^{2}(1, N=241)=0.825, p=.364$.

For training completion, the significant background variable information was:

- 1,500+ Hours: See Table 5

- Total Flight Hours: See Table 6

\section{Discussion}

The primary purpose of this study was to compare pilots who entered initial training at a regional airline in the time period prior to the FOQ ruling with pilots who entered initial training at the same regional airline in the time period after the FOQ ruling. The main areas for comparison were extra training events and training completion. Total flight hours were used to divide the pilots into subgroups within

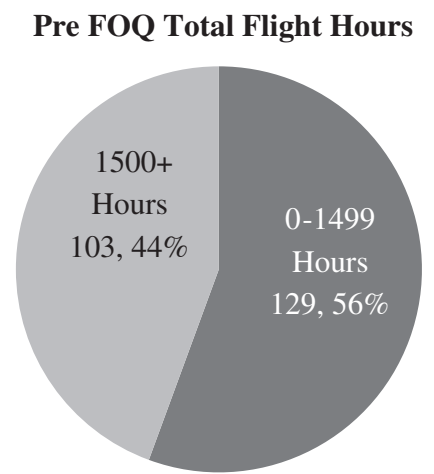

Figure 2. Description of categorical variable, total flight hours within pre FOQ grouping. 
Post FOQ Total Hours

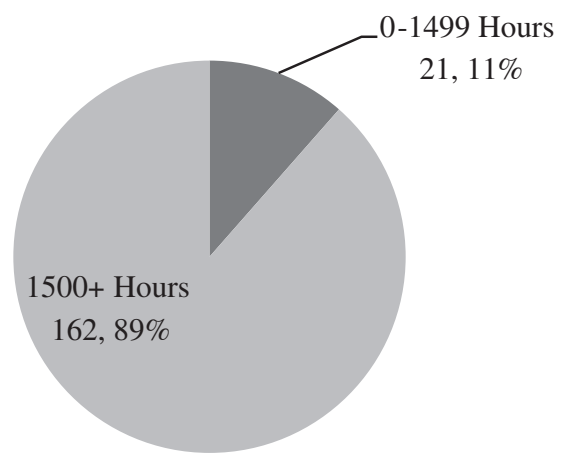

Figure 3. Description of categorical variable, total flight hours within post FOQ grouping.

each FOQ grouping. The main findings of this study can be stated as follows:

- Pilots who entered initial training after the FOQ ruling were more likely to require extra training events and less likely to complete training than those who entered initial training prior to the FOQ ruling.

- Pilots with 1,500 or more total hours who entered initial training after the FOQ ruling were more likely to require extra training events and less likely to complete training than those pilots with 1,500 or more total hours who entered initial training prior to the FOQ ruling.

- There was no significant difference in extra training events or training completion between pilots with 0-1,499 hours who entered initial training after the FOQ ruling and pilots with 0-1,499 hours who entered initial training prior to the FOQ ruling.

The first stated result is relevant because pilots hired after the FOQ ruling were all required to hold an ATP certificate, which supposedly makes them the most qualified pilots to hold the position. However, the analysis shows that the pilot group hired after the FOQ ruling was not as successful in initial training as those hired prior to the FOQ ruling. Moreover, the mean for total flight hours for the pilots hired after the FOQ ruling was 3,095.10, while the mean for total flight hours for pilots hired prior to the FOQ ruling was 1,654.43. Even with a significantly higher mean for total flight hours, the pilots hired after the FOQ ruling still had more extra training events and fewer training completions than the pre FOQ grouping. If all pilots are now required to hold an ATP, the standard issuance of which has a requirement of 1,500 total hours, and more total flight hours supposedly make a pilot safer, it is interesting that the group with a significantly higher mean for total flight hours appears to have been less successful in initial training. It is beyond the scope of this study to determine the reasoning for these results; however, the analysis does beg the question of why it has happened.

The second stated result is relevant for a similar reason to the first stated result. If all pilots are now required to hold an ATP, the standard issuance of which is 1,500 hours, then the fact that there is a significant difference in extra training events and training completions between pilots in this hour subgroup who were hired after the FOQ ruling and the pilots in this hour subgroup who were hired prior to the FOQ ruling is also interesting. Again, it is beyond the scope of this study to be able to explain why this is the case, but it certainly is somewhat perplexing, given the intent of the new ruling.

Finally, the last stated result is relevant because it could offer support to a statement made in the 2012 Pilot Source Study:

The results of the current research indicate that commercial pilots were more successful in completing training that those holding an ATP certificate. This would indicate that the quality of experience, not just quantity of hours and certification criteria, better predicts pilot performance at the regional carriers. (Smith et al., 2012)

Table 3

Comparison of extra training events based on 1,500+ flight hours within FOQ grouping.

\begin{tabular}{lcccc}
\hline Hour Grouping & FOQ Grouping & & Extra Training (Yes) & Extra Training (No) \\
\hline $1500+$ & Pre FOQ & Observed/Expected & $8 / 24.7$ & $95 / 78.3$ \\
$1500+$ & Post FOQ & Std. Residual & -3.4 & 1.9 \\
& & Observed/Expected & $53 / 36.3$ & $98 / 114.7$ \\
\hline
\end{tabular}

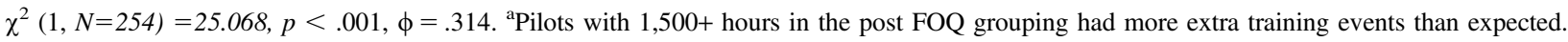

Table 4

Comparison of extra training events based on total flight hours within FOQ grouping.

\begin{tabular}{lccc}
\hline Hour Grouping & FOQ Grouping & & Extra Training (Yes) \\
\hline Total Hours & Pre FOQ & Observed/Expected & $21 / 44.2$ \\
Total Hours & & Std. Residual & -3.5 \\
& Post FOQ & Observed/Expected & $56 / 32.8^{\mathrm{b}}$ \\
& & Std. Residual & 1.7 \\
\hline
\end{tabular}

$\chi^{2}(1, N=404)=35.378, p<.001, \phi=.296 .{ }^{\mathrm{b}}$ Pilots in the post FOQ grouping had more extra training events than expected. 
Table 5

Comparison of training completion based on 1,500+ flight hours within FOQ grouping.

\begin{tabular}{lcccc}
\hline Hour Grouping & FOQ Grouping & & Training Completion (Yes) & Training Completion (No) \\
\hline $1500+$ & Pre FOQ & Observed/Expected & $100 / 95.3$ & $3 / 7.7$ \\
\multirow{2}{*}{$1500+$} & & Std. Residual & .5 & -1.7 \\
& Post FOQ & Observed/Expected & $123 / 127.7$ & $15 / 10.3$ \\
& & Std. Residual & -.4 & 1.5 \\
\hline
\end{tabular}

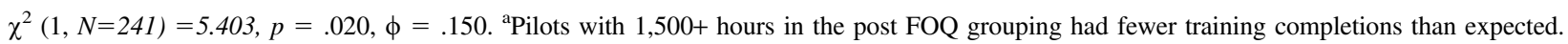

Table 6

Comparison of training completion based on total flight hours within FOQ grouping.

\begin{tabular}{lcccc}
\hline Hour Grouping & FOQ Grouping & & Training Completion (Yes) & Training Completion (No) \\
\hline Total Hours & Pre FOQ & Observed/Expected & $223 / 217.6$ & $9 / 14.4$ \\
Total Hours & & Std. Residual & .4 & -1.4 \\
& Post FOQ & Observed/Expected & $140 / 145.4$ & $15 / 9.6$ \\
& & Std. Residual & -.4 & $1.7^{\mathrm{b}}$ \\
\hline
\end{tabular}

$\chi^{2}(1, N=363)=5.370, p=.020, \phi=.122 .{ }^{b}$ Pilots in the post FOQ grouping had fewer training completions than expected.

While pilot background information, including college degree, major, and type of training, were not collected for this study and, therefore, cannot be used to fully support this argument, one might surmise that all the pilots in the 0-1,499 hour subgroup who entered initial training after the FOQ ruling possessed some form of the R-ATP. This would mean that those pilots either had a military flight background or a college education (bachelor's or associate's degree) with a major in aviation. Again, there is no solid evidence to support this argument, but this might be an explanation as to why there was no significant difference in extra training events or training completion between the FOQ groups for those pilots with $0-1,499$ hours.

\section{Recommendations for Further Research}

Because this is the first study to examine the impact of the FOQ ruling on pilot initial training, it is evident that further research is required to both validate and explain the results presented here. This study was performed on a small scale with limited data points. Future studies should focus on a more robust pilot sample, additional airlines, and additional data points, to include many of those utilized in both the 2010 and 2012 Pilot Source Study.

Although not directly related to this topic of study, the pilot supply and impending pilot shortage should also be examined as possible relevant factors that might play a role in pilot success in initial training. This suggestion was also made in the 2012 Pilot Source Study (Smith et al., 2012). With a depleting pool of applicants and the need to fill pilot slots at regional airlines, perhaps the quality of pilots that might have once made it through initial training without any difficulty is no longer available to regional carriers.

\section{Conclusion}

There is no doubt that the FOQ ruling is a "hot topic" and a somewhat controversial subject in the airline industry. For this reason, the more we as an industry can understand its effect on pilot quality and success, the better and safer we will be in the long run. Some might argue that Congress and the FAA need to change the ruling immediately. While this may be a recommendation and the ultimate solution in the end, the FOQ ruling has been in effect for only a short time, and there is still so much to learn about its impact on pilots, air carriers, and the industry as a whole. However, even though the study explained here was completed on a small scale, the research does show that pilots hired since the FOQ ruling have been less successful in initial training at a regional carrier than those hired prior to the FOQ ruling.

\section{References}

Airline Safety and Federal Aviation Administration Extension Act of 2010. Pub.L. 111-216, 124 Stat, 2348. (2010).

Certification: Pilots, Flight Instructors, and Ground Instructors, 14 C.F.R. §61. (2014).

Depperschmidt, C. L. (2013). Public Law 111-216: Effects of new legislation on collegiate aviation flight training programs. Collegiate Aviation Review, 31, 1-16.

Federal Aviation Administration (2010, July 16). First Officer Qualifications Aviation Rulemaking Committee, Charter. Washington, DC: Department of Transportation.

Federal Aviation Administration. (2013a, July 10). FAA boosts aviation safety with new pilot qualification standards. Retrieved from http:// www.faa.gov/news/press_releases/news_story.cfm?newsId=14838.

Federal Aviation Administration. (2013b, July 12). Advisory Circular 61-139. Institution of higher education's application for authority to certify its graduates for an Airline Transport Pilot certificate with 
reduced aeronautical experience. Washington, DC: Department of Transportation.

Federal Aviation Administration. (2013, July 26). Pilot certification and qualification requirements for air carrier operations (Docket No. FAA-2010-0100; Notice No. Amdt. Nos. 61-130; 121-365; 135-127; 141-1; 142-9). Washington, DC: Department of Transportation.

National Transportation Safety Board. (2010) Colgan Air, Inc. operating as Continental Connection Flight 3407 Bombardier DHC-8-400, N200WQ Clarence Center, New York February 12, 2009 (NTSB/AAR-10/01). Washington, DC: National Transportation Safety Board.

Smith, G. M., Bjerke, E., NewMyer, D. A., Niemczyk, M., \& Hamilton, R. A. (2010). Pilot source study: An analysis of pilot backgrounds and subsequent success in U.S. regional airline training programs. International Journal of Applied Aviation Studies, 10(1), 73-96.

Smith, G. M., Herchko, D., Bjerke, E., Niemczyk, M., Nullmeyer, R., Paasch, J., \& NewMyer, D. A. (2013). The 2012 Pilot Source Study (phase III): Response to the pilot certification and qualification requirements for air carrier operations. Journal of Aviation Technology and Engineering, 2(2), 13-23. http://dx.doi.org/10.7771/2159-6670.1071

Sperlak, L. A., Geske, R. C., Johnson, M. E., \& Schreckengast, S. (2014, January 17). An evaluation into pilot proficiency assessment and the current state of training in the industry. Aviation/Aeronautics/ Aerospace International Research Conference. Paper 34. Retrieved from http://commons.erau.edu/aircon/2014_Challenges_Facing_our_ Industry/january-17-2014/34. 